GENERAL GYNECOLOGY

\title{
Improving quality of care: development of a risk-adjusted perioperative morbidity model for vaginal hysterectomy
}

\author{
Christine A. Heisler, MD; Giovanni D. Aletti, MD; Amy L. Weaver, MS; \\ L. Joseph Melton III, MD; William A. Cliby, MD; John B. Gebhart, MD, MS
}

OBJECTIVE: We sought to develop and evaluate a risk-adjusted perioperative morbidity model for vaginal hysterectomy.

STUDY DESIGN: Medical records of women who underwent vaginal hysterectomy during 2004 and 2005 were retrospectively reviewed. Morbidity included hospital readmission, reoperation, and unplanned medical intervention or intensive care unit admission; urinary tract infections were excluded. Multivariate logistic regression identified factors associated with perioperative morbidity (adjusted for urinary tract infection). The resulting model was validated using a random 2006 sample.

RESULTS: Of 712 patients, 139 (19.5\%) had morbidity associated with congestive heart failure or prior myocardial infarction, perioperative he- moglobin decrease $>3.1 \mathrm{~g} / \mathrm{dL}$, preoperative hemoglobin $<12.0 \mathrm{~g} / \mathrm{dL}$, and prior thrombosis (c-index $=0.68$ ). Predicted morbidity was similar to observed rates in the validation sample.

CONCLUSION: History of congestive heart failure or myocardial infarction, prior thrombosis, perioperative hemoglobin decrease $>3.1 \mathrm{~g} / \mathrm{dL}$, or preoperative hemoglobin $<12.0 \mathrm{~g} / \mathrm{dL}$ were associated with increased perioperative complications. Quality improvement efforts should modify these variables to optimize outcomes.

Key words: perioperative morbidity, risk adjustment, vaginal hysterectomy

Cite this article as: Heisler CA, Aletti GD, Weaver AL, et al. Improving quality of care: development of a risk-adjusted perioperative morbidity model for vaginal hysterectomy. Am J Obstet Gynecol 2010;202:137.e1-5.

A $s$ in other surgical specialties, quality improvement efforts in gynecologic surgery are gaining momentum. Recently, a large national prospective assessment of morbidity after benign hysterectomy was performed in Finland. ${ }^{1}$

From the Divisions of Gynecologic Surgery (Drs Heisler, Aletti, Cliby, and Gebhart) and Biomedical Informatics and Biostatistics (Ms Weaver) and the Divisions of Epidemiology and Endocrinology, Diabetes, Metabolism, and Nutrition (Dr Melton), Mayo Clinic, Rochester, MN.

Presented at the 29th Annual Scientific Meeting of the American Urogynecologic Society, Chicago, IL, Sept. 4-6, 2008.

Received Jan. 26, 2009; revised April 24, 2009; accepted June 24, 2009.

Reprints: John B. Gebhart, MD, MS, Division of Gynecologic Surgery, Mayo Clinic, 200 First St. S.W., Rochester, MN 55905.

gebhart.john@mayo.edu.

Supported in part by research Grant RA-30582 from the National Institutes of Health, US Public Health Service.

0002-9378/\$36.00

(c) 2010 Mosby, Inc. All rights reserved. doi: 10.1016/j.ajog.2009.06.059

See Journal Club, page 203
The overall complication rate was $19 \%$, and this was further stratified among different approaches. Intraoperative complication rates for abdominal, vaginal, and laparoscopic procedures were $2.3 \%$, $3.0 \%$, and $3.2 \%$, respectively. The corresponding postoperative inhospital complication rates were $12.3 \%, 16.1 \%$, and $8.4 \%$, respectively. ${ }^{1}$ Although that study described morbidity from vaginal hysterectomy $(\mathrm{VH})$, there was no description of the impact of concomitant urogynecologic procedures. Complications from urogynecologic surgery range from $20 \%$ for minor complications to $0.2 \%$ for major complications, ${ }^{2,3}$ but they are often compared with those from abdominal hysterectomy. As such, the baseline morbidity associated with $\mathrm{VH}$ and the effect of additional reconstructive surgery have been underinvestigated in the literature.

The relatively elective nature of benign gynecologic surgery has led to a delay in the application of morbidity models. In particular, most women undergoing $\mathrm{VH}$ are generally healthy, and surgery frequently is performed because of qualityof-life considerations. Consequently, the surgical risk should be low. In this con- text, quality improvement processes are imperative for identifying characteristics or comorbid conditions that predispose patients undergoing $\mathrm{VH}$ to increased perioperative complications. Morbidity can be decreased if specific modifiable variables are identified that can categorize patients at risk. We hypothesized that specific variables could be identified and that, by creating a risk-adjusted model of morbidity, we could predict patients at risk for adverse outcomes in $\mathrm{VH}$.

\section{Materials and Methods}

This study was a planned secondary analysis on the data of women who underwent VH for benign indications, which was a retrospective cohort study approved by our institutional review board. We retrieved medical records of all women who underwent $\mathrm{VH}$ for benign indications from January 2004 through December 2005. Patients were included if they underwent $\mathrm{VH}$ with or without salpingectomy, oophorectomy, pubovaginal sling placement, or reconstructive pelvic surgery (anterior, posterior, or combined anteroposterior colporrhaphy). Any patient undergoing 
TABLE 1

\section{Patient demographics, medical and surgical characteristics, and perioperative outcomes}

\begin{tabular}{lcl} 
Characteristic & $\begin{array}{l}\text { Model development } \\
\text { cohort }(\mathbf{n = 7 1 2})^{\mathbf{a}}\end{array}$ & $\begin{array}{l}\text { Model validation } \\
\text { cohort }(\mathbf{n}=\mathbf{1 0 0})^{\mathbf{a}}\end{array}$ \\
\hline Mean (SD) age at surgery, y & $52.0(13.3)$ & $54.6(13.5)$ \\
\hdashline White & $608(85.4)$ & $95(95.0)$
\end{tabular}

Primary insurance type

\begin{tabular}{|c|c|c|}
\hline Private & $589(82.7)$ & $74(74.0)$ \\
\hline Public & $110(15.4)$ & $24(24.0)$ \\
\hline None & $8(1.1)$ & $2(2.0)$ \\
\hline Not documented & $5(0.7)$ & 0 \\
\hline lean (SD) BMI, $\mathrm{kg} / \mathrm{m}^{2}$ & $28.2(6.0)$ & $28.2(4.7)$ \\
\hline Prior incontinence surgery & $9(1.3)$ & $2(2.0)$ \\
\hline Prior prolapse surgery & $7(1.0)$ & $1(1.0)$ \\
\hline $\begin{array}{l}\text { Stage } 3 \text { or } 4 \text { prolapse on initial } \\
\text { examination }{ }^{\text {b }}\end{array}$ & $287 / 462(62.1)$ & $40 / 55(72.7)$ \\
\hline
\end{tabular}

examination ${ }^{\mathrm{b}}$

Indication for surgery

\begin{tabular}{|c|c|c|}
\hline Prolapse & $344(48.3)$ & $50(50.0)$ \\
\hline Bleeding & 351 (49.3) & $52(52.0)$ \\
\hline Incontinence & $157(22.1)$ & $22(22.0)$ \\
\hline Other (eg, pain) & $190(26.7)$ & $26(26.0)$ \\
\hline
\end{tabular}

Medical comorbidities

\begin{tabular}{|c|c|c|}
\hline Hypertension & $199(27.9)$ & $30(30.0)$ \\
\hline Congestive heart failure & $4(0.6)$ & 0 \\
\hline Prior myocardial infarction & $7(1.0)$ & $1(1.0)$ \\
\hline Asthma & $60(8.4)$ & $11(11.0)$ \\
\hline Chronic obstructive pulmonary disease & $6(0.8)$ & $1(1.0)$ \\
\hline Emphysema & $3(0.4)$ & 0 \\
\hline Gastrointestinal reflux disease & $71(10.0)$ & $13(13.0)$ \\
\hline Gastric bypass surgery & $7(1.0)$ & $2(2.0)$ \\
\hline Diabetes mellitus & $36(5.1)$ & $2(2.0)$ \\
\hline Thyroid disorder & $106(14.9)$ & $12(12.0)$ \\
\hline Cerebrovascular accident & $9(1.3)$ & $2(2.0)$ \\
\hline Dementia & $2(0.3)$ & 0 \\
\hline $\begin{array}{l}\text { Preoperative creatinine value } \geq 1.2 \\
\mathrm{mg} / \mathrm{dL}\end{array}$ & 47/692 (6.8) & $5 / 99(5.1)$ \\
\hline Hemoglobin $<12.0 \mathrm{~g} / \mathrm{dL}$ & 95/694 (13.7) & $12(12.0)$ \\
\hline Prior thrombosis & $23(3.2)$ & $3(3.0)$ \\
\hline Tobacco use & $87(12.2)$ & $7(7.0)$ \\
\hline Corticosteroid use within past year & $18(2.5)$ & $2(2.0)$ \\
\hline A classification 1 or 2 & 638/706 (90.4) & $92 / 98(93.9)$ \\
\hline
\end{tabular}

Surgical procedures performed

Oophorectomy (bilateral or unilateral)

504 (70.8)

$72(72.0)$

Salpingectomy (bilateral or unilateral)

$522(73.3)$

77 (77.0) additional nongynecologic procedures, including laparoscopy, was excluded. Medical records were reviewed for demographics, baseline medical status, perioperative findings, surgical procedures, and complications within 9 weeks after the index surgery. Morbidity outcomes included hospital readmission, reoperation, unplanned intensive care unit admission, or any medical problem requiring intervention (eg, antibiotics for infection, blood transfusion for symptomatic anemia, and diuretics for fluid overload). Because urinary tract infection (UTI) was considered a common and relatively minor complication, UTI and antibiotics given for UTI were not considered among the morbidity outcomes.

Composite medical and surgical diagnoses, including a history of congestive heart failure, myocardial infarction, or a thrombotic event, were identified through the initial preoperative surgical consultation and anesthesia medical examination. Standard preoperative laboratory tests included a complete blood cell count, creatinine, and serum glucose. A complete blood cell count was obtained the day after surgery, allowing for comparison of preoperative and postoperative hemoglobin values to determine the absolute decrease in hemoglobin.

Multivariate logistic regression models were fit, using stepwise and backward selection, to identify factors significantly associated with non-UTI perioperative morbidity after forcing type of surgery into the model ( $\mathrm{VH}$ with or without salpingectomy/oophorectomy vs more complex surgery). A $P$ value criterion of $<.05$ was set for variables to be included in the model. Associations were summarized by calculating odds ratio $(\mathrm{OR})$ and corresponding $95 \%$ confidence interval (CI) using the parameter estimates from the model. The predictive ability of the final model was summarized using the c-index ("c" for concordance) proposed by Harrell et al. ${ }^{4} \mathrm{~A}$ c-index ranges from $0-1 ; 1.0$ indicates that the variables in the model perfectly separate women with and without perioperative non-UTI morbidity, and 0.5 indicates that the variables contain discriminant informa- 
tion equal to that obtained by chance alone.

The resulting model was validated with data from a computer-generated random sample of 100 women who underwent $\mathrm{VH}$ for benign indications at our institution in 2006 and had complete records through the postoperative evaluation. In this way, we calculated expected and observed complication rates for validation. All calculated $P$ values were 2 -sided, and $P<.05$ was considered statistically significant. Analyses were performed using a software package (SAS; SAS Institute Inc., Cary, NC).

\section{RESUlTS}

Of the 736 women who met the inclusion criteria, 712 had complete records through the postoperative evaluation and were included in the final analysis. Table 1 summarizes patient characteristics. The model was developed using 712 patients, of whom 139 (19.5\%) had nonUTI morbidity within 9 weeks after VH. Table 2 summarizes the most important variables predicting morbidity. The following variables were found to be significantly associated with increased morbidity: congestive heart failure, prior myocardial infarction, or both (OR, 13.0; 95\% CI, 2.7-63.5); difference in postoperative hemoglobin value of $>3.1$ $\mathrm{g} / \mathrm{dL}$ from preoperative levels (OR, 2.4; 95\% CI, 1.6-3.8); a preoperative hemoglobin value $<12.0 \mathrm{~g} / \mathrm{dL}$ (OR, 3.3; 95\% CI, 1.9-5.5); and prior thrombosis (OR, 2.7; 95\% CI, 1.0-6.8).

The c-index, summarizing the overall predictive ability of this model, was 0.68 and 0.69 , based on the model development cohort and the model validation cohort, respectively. The predicted probabilities of having non-UTI morbidity, as estimated by the model, were similar to the observed rates in the validation sample (Table 3). For example, among patients with decreased hemoglobin $<12.0 \mathrm{~g} / \mathrm{dL}$ as their sole risk factor, the predicted probability of nonUTI morbidity was $29 \%$ (95\% CI, $21-$ $39 \%)$, compared with an observed rate of $20 \%$ in the validation sample.
TABLE 1

\section{Patient demographics, medical and surgical characteristics, and perioperative outcomes (continued)}

\begin{tabular}{|c|c|c|}
\hline Characteristic & $\begin{array}{l}\text { Model development } \\
\text { cohort }(\mathrm{n}=712)^{\mathrm{a}}\end{array}$ & $\begin{array}{l}\text { Model validation } \\
\text { cohort }(n=100)^{a}\end{array}$ \\
\hline Reconstructive pelvic surgery & $336(47.2)$ & $49(49.0)$ \\
\hline Anterior colporrhaphy & $24(3.4)$ & $11(11.0)$ \\
\hline Posterior colpoperineorrhaphy & $16(2.3)$ & $3(3.0)$ \\
\hline $\begin{array}{l}\text { Combined anteroposterior } \\
\text { colporrhaphy }\end{array}$ & $296(41.6)$ & $35(35.0)$ \\
\hline Midurethral sling placement & $118(16.6)$ & $20(20.0)$ \\
\hline Suprapubic catheter & $271(38.1)$ & $43(43.0)$ \\
\hline $\begin{array}{l}\text { Noncomplex surgery (VH with or without } \\
\text { salpingectomy or oophorectomy) }\end{array}$ & $348(48.9)$ & $48(48.0)$ \\
\hline
\end{tabular}

Anesthesia type

\begin{tabular}{|c|c|c|}
\hline General & $528(74.2)$ & $80(80.0)$ \\
\hline Spinal & $181(25.4)$ & $20(20.0)$ \\
\hline Epidural & $3(0.4)$ & 0 \\
\hline lean (SD) estimated blood loss, mL & $274.7(154.2)$ & $289.8(126.2)$ \\
\hline ransfusion & $29(4.1)$ & $2(2.0)$ \\
\hline $\begin{array}{l}\text { lean }(\mathrm{SD}) \text { change in hemoglobin } \\
\text { reoperative-postoperative), } \mathrm{g} / \mathrm{dL}\end{array}$ & $2.7(1.2)$ & $2.6(0.9)$ \\
\hline $\begin{array}{l}\text { hange in hemoglobin (preoperative- } \\
\text { ostoperative) }>3.1 \mathrm{~g} / \mathrm{dL}\end{array}$ & 203/693 (29.3) & 22/96 (22.3) \\
\hline lean (SD) uterine weight, $g$ & $141.4(109.7)$ & $126.0(104.5)$ \\
\hline terine weight $>250 \mathrm{~g}$ & $81(11.4)$ & $8(8.0)$ \\
\hline lean (SD) length of hospitalization, d & $2.4(1.1)$ & $2.2(1.2)$ \\
\hline ny complication & $224(31.5)$ & $26(26.0)$ \\
\hline Any non-UTI complication & $139(19.5)$ & $15(15.0)$ \\
\hline
\end{tabular}

Complications

\begin{tabular}{|c|c|c|}
\hline Unplanned ICU admission & $7(1.0)$ & $1(1.0)$ \\
\hline Hospital readmission & $24(3.4)$ & $3(3.0)$ \\
\hline Reoperation & $17(2.4)$ & $2(2.0)$ \\
\hline Medical problem requiring & $97(13.6)$ & $14(14.0)$ \\
\hline
\end{tabular}

intervention ${ }^{\mathrm{C}}$

Type of complication

\begin{tabular}{|c|c|c|}
\hline Cardiopulmonary & $19(2.7)$ & $1(1.0)$ \\
\hline Thromboembolic & $15(2.1)$ & 0 \\
\hline Infectious (not including UTI) & $18(2.5)$ & $4(4.0)$ \\
\hline Genitourinary & $37(5.2)$ & $7(7.0)$ \\
\hline Bleeding & $34(4.8)$ & $3(3.0)$ \\
\hline Neurologic & $14(2.0)$ & $2(2.0)$ \\
\hline Anesthesia related & 0 & 0 \\
\hline
\end{tabular}

$A S A$, American Society of Anesthesiologists; BMI, body mass index; ICU, intensive care unit; UTI, urinary tract infection; VH, vaginal hysterectomy.

${ }^{\text {a }}$ No. of patients (\%), unless otherwise stated; ${ }^{b}$ Percentage of those with documented stage at initial consultation-prolapse may or may not have been the indication for surgery; ${ }^{\mathrm{C}}$ Including antibiotics for infection (excluding for UTI), blood transfusion for symptomatic anemia, and diuretics for fluid overload.

Heisler. Development of a risk-adjusted perioperative morbidity model for VH. Am J Obstet Gynecol 2010. 
TABLE 2 Summary of patient characteristics evaluated for association
with perioperative morbidity in the model development cohort

\begin{tabular}{|c|c|c|}
\hline \multirow[b]{2}{*}{ Patient characteristic } & \multicolumn{2}{|l|}{ OR (95\% Cl) } \\
\hline & Univariate & Multivariate $^{\mathrm{a}}$ \\
\hline Age at surgery, $\mathrm{y}^{\mathrm{b}}$ & \multicolumn{2}{|l|}{$1.05(0.91-1.20)$} \\
\hline $\mathrm{BMI}^{\mathrm{c}}$ & \multicolumn{2}{|l|}{$1.00(0.97-1.03)$} \\
\hline Stage 3 or 4 prolapse (vs 1 or 2 ) & \multicolumn{2}{|l|}{$1.53(0.95-2.47)$} \\
\hline \multicolumn{3}{|l|}{ Medical comorbidities } \\
\hline CHF, prior MI, or both & $17.41(3.66-82.90)$ & $13.00(2.66-63.52)$ \\
\hline COPD or emphysema & \multicolumn{2}{|l|}{$3.37(0.89-12.70)$} \\
\hline Gastric bypass surgery & \multicolumn{2}{|l|}{$1.66(0.32-8.64)$} \\
\hline Diabetes mellitus & \multicolumn{2}{|l|}{$1.63(0.77-3.47)$} \\
\hline Hemoglobin $<12.0 \mathrm{~g} / \mathrm{dL}$ & $2.28(1.42-3.68)$ & $3.26(1.94-5.48)$ \\
\hline Prior thrombosis & $1.85(0.74-4.58)$ & $2.65(1.03-6.84)$ \\
\hline Corticosteroid use in previous year & \multicolumn{2}{|l|}{$2.71(1.03-7.12)$} \\
\hline Creatinine $\geq 1.2 \mathrm{mg} / \mathrm{dL}$ & \multicolumn{2}{|l|}{$1.62(0.83-3.17)$} \\
\hline ASA class 3 or 4 (vs 1 or 2 ) & \multicolumn{2}{|l|}{$2.22(1.29-3.84)$} \\
\hline Complex surgery (vs VH with/without SO) & $1.66(1.14-2.42)$ & $1.47(0.97-2.22)$ \\
\hline $\begin{array}{l}\text { Change in hemoglobin (preoperative- } \\
\text { postoperative), } \mathrm{g} / \mathrm{dL}^{\mathrm{d}}\end{array}$ & \multicolumn{2}{|l|}{$1.46(1.24-1.71)$} \\
\hline $\begin{array}{l}\text { Change in hemoglobin (preoperative- } \\
\text { postoperative) }>3.1 \mathrm{~g} / \mathrm{dL}\end{array}$ & $2.20(1.49-3.25)$ & $2.44(1.59-3.75)$ \\
\hline Uterine weight $>250 \mathrm{~g}$ & $0.85(0.46-1.55)$ & \\
\hline \multicolumn{3}{|c|}{$\begin{array}{l}A S A \text {, American Society of Anesthesiologists; } B M I \text {, body mass index; } C H F \text {, congestive heart failure; } \mathrm{Cl} \text {, confidence interval; } \\
C O P D \text {, chronic obstructive pulmonary disease; } M I \text {, myocardial infarction; } O R \text {, odds ratio; } S O \text {, salpingo-oophorectomy; } V H \text {, } \\
\text { vaginal hysterectomy. }\end{array}$} \\
\hline \multicolumn{3}{|c|}{$\begin{array}{l}\text { a Multivariate logistic regression model was fit, using stepwise and backward selection, to identify factors associated with } \\
\text { non-urinary tract infection morbidity, after forcing type of surgery (NH with or without salpingectomy or oophorectomy vs more } \\
\text { complex surgery) in the model; }{ }^{\mathrm{b}} \text { OR per } 10 \text {-year increase in age; }{ }^{\mathrm{c}} \text { OR per } 1-\mathrm{kg} / \mathrm{m}^{2} \text { increase in BMl; }{ }^{\mathrm{d}} \text { OR per } 1-\mathrm{g} / \mathrm{dL} \text { decrease } \\
\text { in hemoglobin. }\end{array}$} \\
\hline \multicolumn{3}{|c|}{ Heisler. Development of a risk-adjusted perioperative morbidity model for VH. Am J Obstet Gynecol 2010.} \\
\hline
\end{tabular}

\section{Comment}

We identified variables that predispose women undergoing benign $\mathrm{VH}$ to increased perioperative morbidity: congestive heart failure or prior myocardial infarction, change in hemoglobin of $>3.1 \mathrm{~g} / \mathrm{dL}$, preoperative hemoglobin value $<12.0 \mathrm{~g} / \mathrm{dL}$, and prior thrombosis. Although 47\% (336/712) of the women had $\mathrm{VH}$ with concomitant pelvic reconstructive surgery, complexity of surgery was not significantly associated with increased perioperative morbidity in this model. Determining risk-adjusted rates of complications allows providers to have greater impact on patient care. Ultimately, risk adjustment allows for relevant outcome comparisons to optimize patient and procedure selection. This is the key to quality improvement. ${ }^{5}$

Within the context of general surgery, the most important project in quality improvement is the National Surgical Quality Improvement Program. ${ }^{6}$ This program was started in the Veterans Health Administration and subsequently involved other centers. Briefly, data from different participant hospitals are centrally analyzed, and observed/expected ratios for 30-day mortality and morbidity are generated for each of 8 major surgical specialties. Periodic comparative reports are produced to aid hospital managers and health care providers in identifying structures and processes of care that should be improved. Of interest, since the program started in 1991, the 30day morbidity after major surgery has decreased by $45 \%$, and the 30-day mortality has decreased by $31 \%{ }^{6}$

On the basis of this approach, our gynecologic oncology division piloted a multiinstitutional study that defined risk factors predicting major morbidity, perioperative mortality, length of hospitalization, and ability to receive the planned chemotherapy in patients with advanced ovarian carcinoma. ${ }^{7}$ Specifically, endogenous patient factors (age, American Society of Anesthesiologists classification, preoperative albumin level) and complexity of surgery were primary factors for increased morbidity in ovarian cancer surgery. ${ }^{7}$

Various studies have reported perioperative complication rates among patients undergoing benign gynecologic surgery. Lambrou et $\mathrm{al}^{3}$ estimated the prevalence of perioperative morbidity in reconstructive pelvic surgery to be $46 \%$, with $86 \%$ of the study sample having 1 or more preexisting chronic medical illness. Bai et $\mathrm{al}^{2}$ compared complication rates between women undergoing abdominal hysterectomy or adnexectomy and those undergoing reconstructive pelvic surgery ( $26.7 \%$ vs $34.4 \%$, respectively). The biggest predictors of morbidity were intraoperative blood loss $>1000 \mathrm{~mL}$, decrease in hemoglobin $>3.1 \mathrm{~g} / \mathrm{dL}$, and longer duration of surgery. These studies support the relationship between specific variables and complications; however, until now no models existed to predict adverse outcomes in VH.

This retrospective review is limited in that not all outcome measures can be assessed and some important variables may have been excluded. Additionally, postoperative complications were determined through 9 weeks after surgery. It is possible that complications occurred after that time and were missed. The $97 \%$ data abstraction for the entire cohort (712/736 patients) may minimize this concern, however. Also, any adverse event occurring $>2$ months after surgery may not be immediately related to surgery. Another limitation is that perioperative outcome was not subjectively evaluated, although this was not the fo- 


\section{TABLE 3 \\ Predicted probability of having a complication estimated from the main cohort vs observed rates in validation sample ${ }^{a}$}

\begin{tabular}{|c|c|c|c|c|c|c|}
\hline \multicolumn{4}{|c|}{ Risk factor } & \multirow[b]{2}{*}{$\begin{array}{l}\text { Patients in original } \\
\text { cohort }(n=694)^{b}\end{array}$} & \multirow{2}{*}{$\begin{array}{l}\text { Predicted probability } \\
\text { of complicationc } \\
(95 \% \text { Cl) }\end{array}$} & \multirow{2}{*}{$\begin{array}{l}\text { Observed complications } \\
\text { in validation sample } \\
(n=100)^{d}\end{array}$} \\
\hline $\begin{array}{l}\text { CHF or } \\
\text { MI }\end{array}$ & $\begin{array}{l}\text { Decrease in } \mathrm{Hb} \\
>3.1 \mathrm{~g} / \mathrm{dL}\end{array}$ & $\begin{array}{l}\text { Preoperative } \mathrm{Hb} \\
<12 \mathrm{~g} / \mathrm{dL}\end{array}$ & $\begin{array}{l}\text { DVT or } \\
\text { PE }\end{array}$ & & & \\
\hline- & - & - & - & 389 & $12 \%(9-15)$ & $7 / 63(11 \%)$ \\
\hline- & - & - & + & 17 & $26 \%(12-47)$ & \\
\hline- & - & + & - & 78 & $29 \%(21-39)$ & $2 / 10(20 \%)$ \\
\hline- & + & - & - & 185 & $26 \%(20-32)$ & $4 / 19(21 \%)$ \\
\hline+ & - & - & - & 2 & $65 \%(27-90)$ & \\
\hline- & - & + & + & 3 & $52 \%(29-75)$ & \\
\hline- & + & - & + & 2 & $48 \%$ (26-72) & $1 / 2(50 \%)$ \\
\hline- & + & + & - & 10 & $52 \%(38-66)$ & $0 / 1$ \\
\hline+ & - & + & - & 2 & $85 \%(53-97)$ & \\
\hline+ & + & - & - & 6 & $83 \%$ (50-96) & \\
\hline+ & - & + & + & 0 & 0 & $0 / 1$ \\
\hline
\end{tabular}

$C H F$, congestive heart failure; $C$, confidence interval; $D V T$, deep vein thrombosis; $H b$, hemoglobin; $M I$, myocardial infarction; $P E$, pulmonary embolism.

a Predicted probability of having perioperative morbidity as estimated from the main cohort using a model that did not include surgical complexity, compared with the observed complication rates in the validation sample, according to the presence or absence of independent risk factors in the final model; ${ }^{b}$ Number of patients in original cohort-18 patients were missing data on preop Hb level and were not included; ${ }^{c}$ Complications were defined as unplanned intensive care unit admission, hospital readmission, reoperation, or medical intervention (eg, antibiotics for infection excluding urinary tract infection, blood transfusion for symptomatic anemia, and diuretics for fluid overload); ${ }^{\mathrm{d}}$ Number of patients in validation sample with complications out of the number with a particular combination of risk factors- 4 patients were missing data on preoperative $\mathrm{Hb}$ level and were not included (1 of these patients had a complication).

Heisler. Development of a risk-adjusted perioperative morbidity model for VH. Am J Obstet Gynecol 2010.

cus of the study. Last, these operations were performed by high-volume surgeons, which may lead to an underestimation of surgeon-specific variables.

The overall goal of a quality improvement project is to identify existing areas in practice that can be altered to decrease morbidity. Identification of modifiable characteristics would allow surgeons to have a direct effect on decreasing or avoiding complications. Nonmodifiable variables are still important, however, in that they assist the clinician in identifying patients at higher risk before surgery. By considering all these variables, the care of patients can be managed more aggressively (eg, planned postoperative intensive care unit admission), or patients may be counseled more extensively before consenting to surgery to better understand the risks they face.
Prospective studies highlighting methods to decrease adverse events in patients at higher risk will ultimately have the greatest effect on patient outcomes. Such studies are already being conducted in other surgical specialties through the efforts of the National Surgical Quality Improvement Program. ${ }^{6}$ By creating a risk-adjusted model, perioperative complications can be accurately identified and the effects of quality improvement programs adequately measured to improve patient outcomes.

\section{REFERENCES}

1. Makinen J, Johansson J, Tomas $C$, et al. Morbidity of 10110 hysterectomies by type of approach. Hum Reprod 2001;16:1473-8.

2. Bai SW, An JM, Shin JS, Park JH, Kim SK, Park KH. Comparison of perioperative complications between reconstructive pelvic surgery and general gynecologic surgery. Yonsei Med J 2004;45:281-6.
3. Lambrou NC, Buller JL, Thompson JR, Cundiff GW, Chou B, Montz FJ. Prevalence of perioperative complications among women undergoing reconstructive pelvic surgery. Am J Obstet Gynecol 2000;183:1355-8.

4. Harrell FE Jr, Lee KL, Mark DB. Multivariable prognostic models: issues in developing models, evaluating assumptions and adequacy, and measuring and reducing errors. Stat Med 1996;15:361-87.

5. Rowell KS, Turrentine FE, Hutter MM, Khuri SF, Henderson WG. Use of national surgical quality improvement program data as a catalyst for quality improvement. J Am Coll Surg 2007;204:1293-300.

6. Khuri SF. Safety, quality, and the national surgical quality improvement program. Am Surg 2006;72:994-8.

7. Aletti GD, Santillan A, Eisenhauer EL, et al. A new frontier for quality of care in gynecologic oncology surgery: multi-institutional assessment of short-term outcomes for ovarian cancer using a risk-adjusted model. Gynecol Oncol 2007;107:99-106. 